\title{
Penataan Taman Tirto Agung sebagai Ruang Publik di Kecamatan Banyumanik Semarang
}

\author{
Tirto Agung Park Design as Public Space in Subdistrict Banyumanik Semarang
}

\author{
Aulia Finti Alda ${ }^{1}$ \\ Universitas Diponegoro, Semarang, Indonesia \\ Nurini2 \\ Universitas Diponegoro, Semarang, Indonesia
}

\begin{abstract}
Abstrak: Taman sebagai ruang publik harus memenuhi standar yang baik terutama dalam hal perancangan kota dan ketersedian fasilitas. Penyediaan fasilitas tersebut juga perlu disesuaikan terhadap jenis taman dan peninjauan terhadap kebutuhan masyarakat. Dalam hal ini, analisis yang dilakukan bertujuan untuk melakukan penataan taman yaitu dengan menggunakan metode kuantitaf dengan teknik analisa deskriptif. Teknik tersebut berdasarkan pada aspek pengukuran secara objektif terhadap fenomena sosial. Metode analisis yang digunakan untuk mengolah data yaitu analisis karakteristik pengunjung, aspek pendukung taman, serta analisis perancangaan. Selain itu, data yang perlu diperhatikan yaitu tentang jenis fasilitas publik yang relevan, serta data mengenai persepsi masyarakat akan kebutuhan ruang publik. Rencana konsep penataan yang akan diterapkan pada taman Tirto Agung ini yaitu "Banyumanik Green Park". Konsep tersebut menjelaskan tentang suatu taman di Banyumanik yang mempertimbangkan aspek hijau/ lingkungan. Dalam kegiatan penataan pada taman Tirto Agung ini, disesuaikan dengan kebutuhan masyarakat terkait fungsi ekologi, fungsi estetika, fungsi kesehatan, fungsi rekreasi dan fungsi ekonomi dari ruang terbuka hijau, sehingga taman ini dapat digunakan sebagai wadah bagi aktivitas masyarakat kota yang dapat dinikmati oleh semua kelompok umur dengan penataan lansekap yang dapat meningkatkan nilai estetika dari suatu kawasan taman.
\end{abstract}

\section{Kata kunci: ruang publik; penataan; taman}

\begin{abstract}
As a public space, this park must have good standards, especially in terms of urban design and the availability of facilities. The provision of these facilities also need to be tailored to the type of garden and review of the needs of the community. In this case, the analysis conducted aims to make of park design is by using quantitative methods with descriptive analysis techniques. The technique is based on an objective measurement aspect to social phenomena. The analytical methods used to process the data that analyses the characteristics of visitor, park supporters aspects, as well as design analysis. Additionally, data that need to be considered, namely on the relevant public facilities, as well as data on the public perception of the need for public space. Plan of concept design which will be applied to this Tirto Agung park is "Banyumanik Green Park". The concept describes a garden in Banyumanik which to consider aspects green/ environment. In the settlement activities in the Tirto Agung park, tailored to the needs of the community related to ecological function, aesthetic function, health function, the function of recreation and economic functions of green open space, so that the park can be used as a place for community activities the city that can be enjoyed by all groups age with structuring landscaping can enhance the aesthetic value of an area park.
\end{abstract}

Keywords: public space; design; park

\footnotetext{
${ }^{1}$ Korespondensi Penulis: Universitas Diponegoro, Semarang, Indonesia Email: aulia.finti15@pwk.undip.ac.id

2 Korespondensi Penulis: Universitas Diponegoro, Semarang, Indonesia Email: nur1n1@yahoo.com
} 


\section{Pendahuluan}

Kajian Penataan Taman
Taman Tirto Agung merupakan salah satu taman aktif yang baru dibangun oleh Dinas Kebersihan dan Pertamanan Kota Semarang pada tahun 2011 lalu. Sebagai taman yang tergolong baru, dapat dikatakan bahwa taman ini kurang menarik perhatian masyarakat. Hal tersebut ditandai dengan penataan taman yang masih belum baik karena banyak para PKL yang berjualan sembarangan di dalam taman maupun di pinggir jalan. Selain itu, kondisi kebersihan pada taman ini juga belum terjaga karena masih banyak sampah yang berserakan di area taman. Hal ini menunjukan bahwa minimnya elemen pendukung pada taman seperti tempat sampah, lampu taman, maupun bunga/ penghijauan. Pada malam harinya dapat terlihat dengan masih kurangnya pencahayaan, sehingga ada bagian taman yang tidak terdapat sorotan cahaya lampu. Selain masalah tersebut, untuk lokasi parkirnya pun sendiri belum terlihat jelas dimana tempat parkir yang sesungguhnya, karena masih banyak kendaraan yang parkir sembarangan. Sayangnya dengan kondisi taman yang masih buruk tersebut, masyarakat kurang melirik taman tersebut sebagai salah satu tempat alternatif berekreasi, bahkan pada hari liburpun kondisi taman ini tetap sepi. Untuk mengatasi permasalahan tersebut, diperlukan tinjauan kondisi eksisting yang mencakup karakteristik pengunjung, elemen pendukung taman, serta aspek perancangan, sehingga dapat memberikan arahan terhadap penataan taman Tirto Agung yang lebih baik dan dapat meningkatkan kualitasnya sebagai ruang publik. Setelah melakukan tinjauan terhadap rumusan masalah tersebut, maka munculah research question yaitu: Bagaimana konsep penataan taman Tirto Agung sebagai ruang publik di Kecamatan Banyumanik Semarang?

Output dari penelitian ini adalah konsep penataan yang dilakukan pada Taman Tirto Agung yang berupa urban design guideline sehingga dapat menciptakan suatu taman sebagai ruang publik di Kecamatan Banyumanik. Penataan tersebut ditinjau berdasarkan aspek karakteristik pengunjung, elemen pendukung taman, serta aspek perancangan.

Tujuan dari studi ini yaitu melakukan penataan terhadap taman Tirto Agung sebagai ruang publik di Kecamatan Banyumanik Semarang. Untuk mencapai tujuan yang diharapkan, sasaran yang dilakukan yaitu sebagai berikut:

1. Mengidentifikasi karakteristik pengunjung (usia pengunjung, asal pengunjung, kegiatan pengunjung, waktu kunjungan, dan lama berkunjung) pada taman Tirto Agung.

2. Mengidentifikasi elemen pendukung (tampilan depan, bangku, tempat sampah, lampu, bunga, pohon pelindung, pengerasan taman, parkir, pedagang, fasilitas bermain anak, dan fasilitas olahraga) pada taman Tirto Agung.

3. Mengidentifikasi aspek perancangan (aspek tapak, kriteria terukur, kriteria tak terukur, dan elemen estetika) pada taman Tirto Agung.

Ruang lingkup studi terdiri dari 2 hal, yaitu ruang lingkup wilayah dan ruang lingkup substansi. Lokasi penelitian berisikan batas batas fisik wilayah studi, yaitu taman Tirto Agung Banyumanik, sedangkan ruang lingkup substansi berisikan penjabaran dari sasaran penelitian.

Lokasi penelitian adalah taman Tirto Agung Banyumanik yang terletak di jalan Durian dan Jalan Tirto Agung. Taman tersebut berada di antara kawasan permukiman Banyumanik, kawasan pertokoaan di sebelah selatan, dan berbatasan langsung dengan pintu masuk tol banyumanik di sebelah utara. Kawasan taman ini memiliki luas sekitar $0.9 \mathrm{Ha}$, seperti terlihat pada peta di bawah ini:

Secara umum ruang publik terdiri dari ruang publik terbuka dan ruang publik tertutup. Ruang publik dirancang untuk dapat memfasilitasi dan mendukung aktivitas manusia yang terdapat di dalamnya, sehingga berdasarkan penjelasan tersebut dapat diketahui bahwa ruang publik merupakan suatu ruang yang terbentuk atau didesain dengan sedemikian rupa sehingga ruang tersebut dapat menampung sejumlah besar orang (publik) dalam melakukan aktivitas aktivitas yang bersifat publik. 


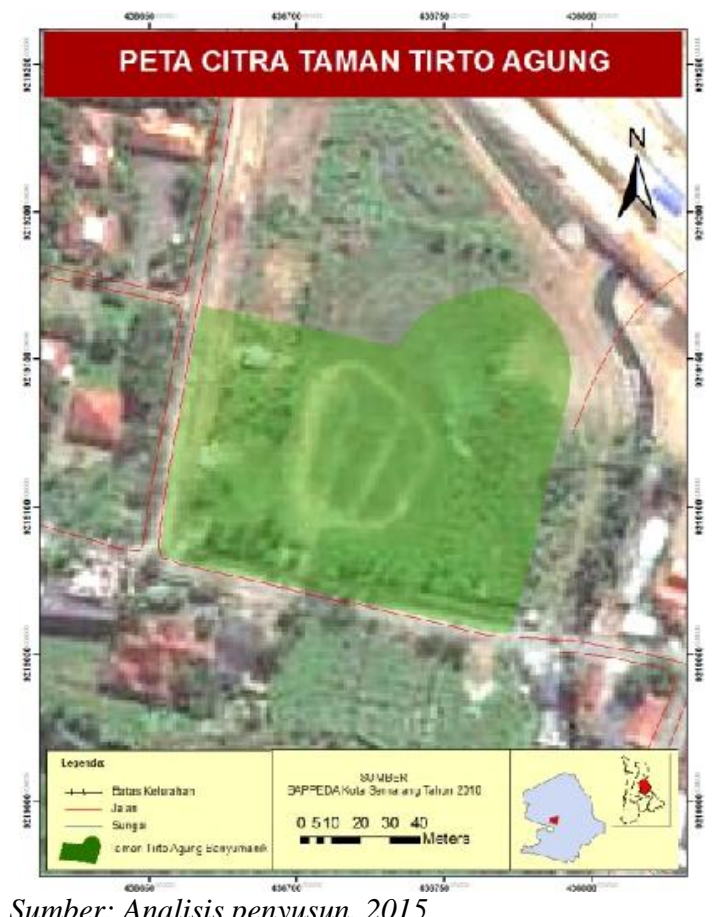

Sumber: Analisis penyusun, 2015

\section{Gambar 1. Peta Administrasi Taman Tirto Agung}

Secara etimologi, Laurie (1994) menyebutkan asal mula pengertian kata taman (garden) berasal dari bahasa lbrani gan yang berarti melindungi atau mempertahankan, menyatakan secara tidak langsung hal pemagaran atau lahan berpagai dengan batas batas tertentu, dan oden atau eden yang berarti kesenangan atau kegembiraan. Jadi, dalam bahasa lnggris perkataan garden memiliki gabungan dari kedua kata kata tersebut yang berarti sebidang lahan yang memiliki batas tertentu yang digunakan untuk kesenangan dan kegembiraan, sehingga dapat dikatakan bahwa taman merupakan sebidang lahan yang ditata sedemikian rupa sehingga mempunyai keindahan, kenyamanan dan keamanan bagi pemiliknya atau penggunanya. Pada masyarakat perkotaan, taman-taman selain bernilai estetika juga berfungsi sebagai ruang terbuka (Arifin dan Nurhayati, 2000).

Sistem taman kota disajikan untuk menginspirasi kehidupan masyarakat dalam bentuk kontak sosial, terutama antara orang orang yang memiliki latar belakang yang berbeda, sehingga menimbulkan rasa kebebasan yang dapat membuat akal menjadi sehat. Menurut Hakim (2003), salah satu fungsi taman adalah nilai estetis, yang dinyatakan bahwa nilai estetika taman diperoleh dari perpaduan antara warna daun, batang, bunga, bentuk fisik tanaman, tekstur tanaman, skala tanaman, komposisi tananaman, sekelompok tanaman yang sejenis, kombinasi antara tanaman dengan elemen lansekap lainnya, kesatuan dalam desain, yaitu variasi, penekanan, keseimbangan, kesederhanaan, dan urutan.

Selain fungsi estetis, taman kota juga memiliki fungsi lain. Menurut Hakim (2003) taman kota sebagai ruang publik memiliki beberapa fungsi sosial antara lain:

a. Tempat bermain dan sarana olahraga

b. Tempat komunikasi sosial

c. Tempat peralihan dan menunggu

d. Tempat untuk mendapatkan udara segar

e. Sarana penghubung antara suatu tempat dengan tempat yang lain

f. Pembatas diantara masa bangunan

g. Sarana penelitan dan pendidikan serta penyuluhan bagi masyarakat untuk membentuk kesadaran lingkungan

h. Sarana untuk menciptakan kebersihan, kesehatan, keserasian dan keindahan lingkungan. 
Analisis Taman Tirto Agung

\section{Analisis Karakteristik Pengunjung}

Usia Pengunjung

Berdasarkan penelitian peneliti, dapat diketahui bahwa sebagian besar pengunjung yaitu orang dewasa (18-45 tahun) sekitar $72 \%$ dari 90 responden, dan yang paling sedikit yaitu golongan lansia atau yang berumur 45 tahun ke atas. Pada taman Tirto Agung ini, banyak terdapat anak anak di bawah umur yang ditemani oleh orang tuanya, sehingga pada hasil diagram terhadap analisis kuesioner yang dilakukan tidak satupun anak anak yang sedang berkunjung, namun kenyataanya mereka yang berusia 0-ll tahun tidak mungkin untuk mengisi kuesioner, sehingga kuesioner tersebut ditujukan kepada orang tuanya.

\section{- Asal Pengunjung}

Dari analisis yang telah dilakukan, pengunjung terbanyak yaitu berasal dari tembalang yaitu sekitar $28 \%$ dari 90 responden. Hal ini dapat dilihat dari lokasi taman yang dekat dengan kampus Undip Tembalang, sehingga banyak mahasiswa yang duduk bersama teman dekat di taman ini. Selain itu, pengunjung taman ini juga didominasi oleh masyarakat Pedalangan itu sendiri dan dari Srondol Kulon yaitu sekitar $10 \%$ dari total pengunjung. Pengunjung lainnya juga ada yang berasal dari luar Semarang, seperti Kendal.

- Kegiatan Pengunjung

Berdasarkan analisis yang telah dilakukan, sebagian besar pengunjung hanya melakukan duduk duduk santai yaitu sebanyak 64\% dari 90 responden.Duduk duduk santai yang dilakukan tersebut bersama teman maupun keluarga.Ada juga orang tua yang menemani anak anak mereka bermain, yang dijadikan sebagai tempat berkumpul keluarga.

\section{- Waktu Berkunjung}

Pengunjung terbanyak yaitu pada sore hari yaitu sebanyak 64\% dari keseluruhan responden. Dari pengamatan responden pada sore hari tersebut, pengunjung mulai memadati taman Tirto Agung ini sekitar pukul 16.00 WIB. Sedangkan pada waktu siang hari tidak ada pengunjung yang mengunjungi taman, dan untuk waktu kunjung paling sedikit yaitu pada pagi hari yaitu kisaran $15 \%$ dari keseluruhan responden.

- Lama Berkunjung

Lama kunjungan yang sering dilakukan oleh pengunjung yaitu kisaran 1-3 jam dengan jumlah $91 \%$ dari 90 responden, dan yang paling sedikit terdapat $2 \%$ dari total sampel pengunjung dengan lama kunjungan selama 6-12 jam.

\section{Analisis Elemen Pendukung Taman}

- Tampilan depan/ landmark, terhadap persebaran kuesioner kepada 90 sampel pengunjung taman, sekitar $50 \%$ dari total pengunjung menganggap landmark atau tampilan depan dari taman ini sudah baik.

- Tempat duduk, dari analisis yang telah dilakukan, ada sekitar 54\% dari 90 responden yang berpendapat bahwa kondisi tempat duduknya sudah baik.

- Tempat sampah, terdapat sekitar $46 \%$ responden yang menganggap kondisi tempat sampahnya sudah baik. Hanya $1 \%$ saja dari 90 orang responden yang menganggap kondisinya sangat baik.

- Lampu, terdapat sekitar 43\% dari 90 responden yang menganggap kondisi lampu sudah baik, selanjutnya memilih dengan kondisi cukup baik, kurang baik, sangat baik, dan hanya $2 \%$ yang mengaggap tidak baik.

- Bunga, dari persebaran kuesioner yang dilakukan terhadap 90 responden pengunjung, terdapat $42 \%$ pengunjung yang menganggap kondisi bunga kurang baik.

- Pohon pelindung/ vegetasi, dari analisis responden tentang pohon pelindung di taman ini, paling banyak menganggap dengan kondisi yang cukup baik atau sekitar 38\% dari 90 responden, dan dilanjutkan dengan $35 \%$ menganggap kondisi kurang baik.

- Pengerasan taman, terdapat sekitar $44 \%$ atau 40 orang dari 90 responden menganggap kondisi pengerasan taman sudah cukup baik. 
- Parkir, menunjukan bahwa sebagian besar pengunjung menilai kondisi parkir sudah cukup baik dengan jumlah $32 \%$ dari 90 responden.

- Pedagang, hasil persebaran kuesioner yang dilakukan terhadap 90 responden, paling banyak menganggap kondisi pedagang cukup baik dengan jumlah $41 \%$ dari 90 responden.

- Fasilitas/ area bermain anak, bahwa sebagian besar atau 34\% dari 90 responden pengunjung menganggap fasilitas bermain anak sudah cukup baik dengan fasilitas bermain yang tersedia hanya ada 3 jenis mainan anak.

- Fasilitas olahraga, dari survey yang dilakukan hanya $40 \%$ saja responden yang berpendapat bahwa fasilitas olahraganya sangat baik.

\section{Analisis Aspek Perancangan}

Analisis Tapak

- Konstelasi wilayah mencakup keterkaitan taman Tirto Agung dengan sekitarnya.

- Analisis lingkungan, berfungsi untuk menentukan kesesuaian zoning suatu taman Tirto Agung berdasarkan fungsi fungsi yang telah ada

- Analisis topografi, dapat diketahui dari garis kontur yang terdapat pada taman Tirto Agung ini yaitu memiliki lereng yang datar.

- Analisis kebisingan, terdiri dari kebisingan tinggi (jalan tol) dan kebisingan rendah (Jalan Tirto Agung dan Jalan Durian).

- Analisis drainase, berupa drainase terbuka yang alirannya ke saluran jalan.

- Analisis view, terdiri dari view to site (sebuah landmark yang dikenali dari jauh yang dijadikan sebagai karakter) dan view from site (adanya fasilitas panjat tebing yang disediakan untuk pengunjung yang ingin belajar).

- Analisis vegetasi, terdapat pohon trembesi sebagai peneduh di pinggir jalan sekaligus dapat mengurangi pencemaran.

- Analisis arah angin dan lintasan matahari, pola limpasan matahari bergerak dari timur ke barat, sedangkan untuk arah angin yang cocok pada suatu ruang publik yaitu angin yang sejuk dan sepoi sepoi

- Zoning kawasan, merupakan pembagian kawasan taman menjadi beberapa zona tertentu.

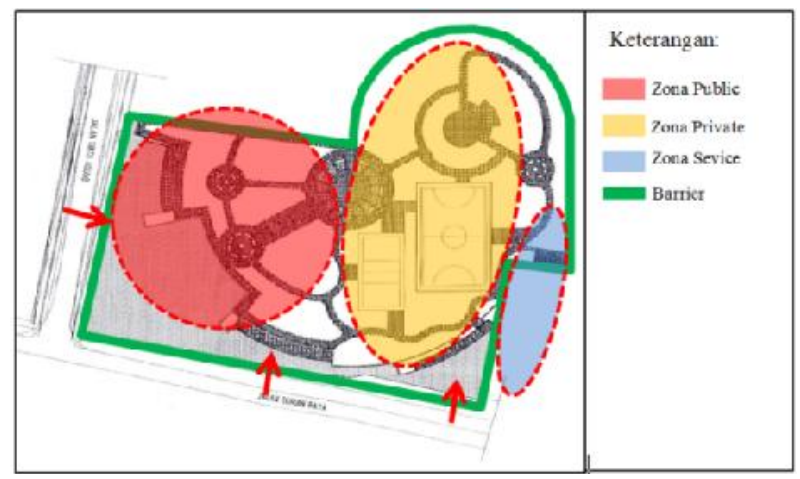

Sumber: Analisis penyusun, 2015

\section{Gambar 2. Zoning Kawasan Taman Tirto Agung}

\section{Analisis Terukur}

- Perhitungan Penyediaan Jogging Track, lebar untuk penyediaan jogging track seharusnya lebih besar dari $1.5 \mathrm{~m}$. Pada taman ini, jarak untuk jogging track yaitu $2 \mathrm{~m} /$ tidak melebihi dari lebar standar.

- Jarak Antar Tanaman, Tanaman yang terdapat yaitu, Johar(10m), Ketapang (3×3m), Ketapang Kencana $(3 \times 3 \mathrm{~m})$, Flamboyan (10x10m), Durian (10x10m), Alpukat (8x8m), sawokecik (4x4m), Mangga (10x10m), Palem sadeng $(<3 \mathrm{~m})$, Tahiayam (1xlm), Ceplok Piring $(0.4 \times 0.4 \mathrm{~m})$, Sambiloto $(0.4 \times 0.5 \mathrm{~m})$, Trembesi $(15 \times 15 \mathrm{~m})$. 
- Standar Ukuran Sarana Olahraga, pada taman ini, ukuran lapangan futsal $17.3 \times 27.1 \mathrm{~m}$, lapangan voly $9 \times 18 \mathrm{~m}$, dan juga terdapat fasilitas panjat tebing dengan jarak pegangan $30 \mathrm{~cm}$. Untuk perhitungan jarak fasilitas olahraga dengan taman bermain tidak mengharuskan ada jarak yang jauh, dan perlu diberi vegetasi sebagai pembatas.

\section{Analisis Tak Terukur}

- Acces, dilalui oleh Jalan Tirto Agung dan Jalan Durian Raya, dan selain itu juga dekat dengan jalan Tol Semarang Solo.

- Compability, mencakup kecocokan topografi dengan taman.

- Identity, yaitu berupa landmark dengan tulisan Taman Tirto Agung sebagai identitas.

- Sense, dapat menciptakan taman bermain aktif bagi keluarga.

- Livability, didesain sebagai taman aktif yang dapat dinikmati oleh semua jenis kelompok umur.

\section{Analisis Elemen Estetika}

- Proporsi, keserasian antara elemen yang berkaitan dengan ukuran, warna, kuantitas, dan layout.

- Hirarki, ditunjukan melalui perbedaan ukuran, bentuk elemen, maupun lokasi yang strategis.

- Irama dan pengulangan, terdiri dari pengulangan unsur lansekap dalam satu pola.

- Konteks dan kontras, terdapat kontras pada bagian pengerasan, serta tumbuhan/ bunga yang di tanam.

- Balance, mencakup keseimbangan komposisi antara unsur yang ada.

Konsep Penataan
Arahan rencana penataan yang akan diterapkan pada taman Tirto Agung yaitu Taman "Banyumanik Green Park". Konsep tersebut menjelaskan tentang suatu taman di Banyumanik yang mempertimbangkan aspek hijau/ lingkungan. Dalam kegiatan penataan pada taman Tirto Agung ini, disesuaikan dengan kebutuhan masyarakat terkait fungsi ekologi, fungsi estetika, fungsi kesehatan, fungsi rekreasi dan fungsi ekonomi dari ruang terbuka hijau. Taman ini dapat digunakan sebagai wadah bagi aktivitas masyarakat kota dengan penataan lansekap yang dapat meningkatkan nilai estetika dari kawasan tersebut.

Dikarenakan lokasi taman Tirto Agung berada di Kecamatan Banyumanik (perbatasan Kota Semarang dengan Kabupaten Semarang) dan jauh dari pusat kota Semarang, maka taman ini dapat dikembangkan dengan konsep ruang terbuka aktif yang mendukung ruang terbuka utama (alun-alun Kota Semarang). Dengan adanya suatu taman kota yang telah memiliki fungsi sebagai ruang publik, diharapkan dapat memenuhi kebutuhan masyarakat akan sarana ruang terbuka di lingkungan sekitar.

\section{Analisis Kebutuhan Ruang dan Fasilitas}

Kebutuhan ruang pada taman Tirto Agung berupa perhitungan terhadap jumlah dan luas ruang yang dibutuhkan dari setiap aktivitas yang terdapat pada lokasi tapak taman. Spesifikasi dari tiap aktivitas yang ada dapat dijadikan sebagai pembeda dengan aktivitas lain. Untuk dapat mengetahui berbagai aktivitas yang ada, dapat terlihat dari pemenuhan kebutuhan ruangnya, seperti analisis yang dilakukan pada tabel di bawah ini:

Tabel I. Analisis Rencana Kebutuhan Ruang

\begin{tabular}{|c|c|c|c|c|c|}
\hline $\begin{array}{l}\text { Kelompok } \\
\text { Aktivitas }\end{array}$ & Jenis Aktifitas & Pengguna & $\begin{array}{l}\text { Jumlah Pengguna } \\
\text { (orang) }\end{array}$ & $\begin{array}{c}\text { Jumlah } \\
\text { (Unit) }\end{array}$ & $\begin{array}{c}\text { Luas } \\
\text { Total }(\mathbf{m})\end{array}$ \\
\hline \multicolumn{6}{|l|}{ Publik } \\
\hline Zona Berkumpul & $\begin{array}{l}\text { Berkumpul dan } \\
\text { duduk duduk santai }\end{array}$ & $\begin{array}{l}\text { Semua } \\
\text { Pengunjung }\end{array}$ & 10289 & - & 1800 \\
\hline $\begin{array}{l}\text { Sirkulasi dan } \\
\text { Parkir }\end{array}$ & Parkir Kendaraan & $\begin{array}{l}\text { Semua } \\
\text { Pengunjung }\end{array}$ & 10289 & 1 & 150 \\
\hline $\begin{array}{l}\text { Fasilitas Olahraga } \\
\text { untuk Lansia }\end{array}$ & Alat olahraga & Para lansia & 1610 & 1 & 40 \\
\hline
\end{tabular}

RUANG (VOL.1) NO. 4, 2015, 171 - 180

DOI: HTTP://DX.DOI.ORG/10.14710/RUANG.1.4.171-180 


\begin{tabular}{|c|c|c|c|c|c|}
\hline $\begin{array}{l}\text { Kelompok } \\
\text { Aktivitas }\end{array}$ & Jenis Aktifitas & Pengguna & $\begin{array}{c}\text { Jumlah Pengguna } \\
\text { (orang) }\end{array}$ & $\begin{array}{l}\text { Jumlah } \\
\text { (Unit) }\end{array}$ & $\begin{array}{c}\text { Luas } \\
\text { Total }\left(\mathrm{m}^{2}\right) \\
\end{array}$ \\
\hline \multicolumn{6}{|l|}{ Privat } \\
\hline \multirow[t]{3}{*}{$\begin{array}{l}\text { Zona Permainan } \\
\text { Anak }\end{array}$} & Sarana Climbing & $\begin{array}{l}\text { Semua } \\
\text { Pengunjung }\end{array}$ & 10289 & 1 & 200 \\
\hline & $\begin{array}{l}\text { Fasilitas Bermain } \\
\text { Anak dari DKP }\end{array}$ & Anak Anak & 2126 & 8 & 320 \\
\hline & $\begin{array}{l}\text { Persewaan Mobil } \\
\text { Mobilan }\end{array}$ & Anak Anak & 2126 & - & 500 \\
\hline \multirow[t]{2}{*}{ Zona Olahraga } & Lapangan Futsal & $\begin{array}{l}\text { Remaja, } \\
\text { dewasa }\end{array}$ & 6550 & 1 & 375 \\
\hline & Lapangan Volly & $\begin{array}{l}\text { Remaja, } \\
\text { dewasa }\end{array}$ & 6550 & 1 & 162 \\
\hline \multicolumn{6}{|l|}{ Pelayanan } \\
\hline Fasilitas Sanitasi & WC Umum & $\begin{array}{l}\text { Semua } \\
\text { Pengunjung }\end{array}$ & 10289 & 4 & $24 \mathrm{~m}$ \\
\hline $\begin{array}{l}\text { Fasilitas } \\
\text { Perdagangan dan } \\
\text { jasa }\end{array}$ & $\begin{array}{l}\text { Stand Pedagang } \\
\text { dan gazebo }\end{array}$ & $\begin{array}{l}\text { Semua } \\
\text { Pengunjung }\end{array}$ & 10289 & 20 & $770 \mathrm{~m}$ \\
\hline \multicolumn{3}{|l|}{ Jogging Track } & & & 1000 \\
\hline \multicolumn{3}{|c|}{ Penghijauan Taman/ Vegetasi } & & & 1100 \\
\hline \multicolumn{3}{|l|}{ Pengerasan Taman } & & & 2279 \\
\hline \multicolumn{3}{|l|}{ Barrier } & & & 600 \\
\hline \multicolumn{3}{|l|}{ Jumlah } & & & 9320 \\
\hline
\end{tabular}

Sumber: Analisis penyusun, 2015

Berdasarkan tinjauan terhadap analisis kebutuhan ruang, maka dapat diperoleh suatu bentuk hubungan antar aktivitas dengan pengguna. Hubungan tersebut menjelaskan keterkaitan antar aktivitas yang diwadahi pada ruang taman. Setelah mengetahui hubungan antar ruang, maka akan menghasilkan suatu bentuk organisasi ruang yang berfungsi untuk mengatur atau menata peletakan aktivitas aktivitas pada tapak taman ini. Dalam hal ini, organisasi ruang dijadikan sebagai penentu dalam pembagian zona aktivitas sesuai dengan kebutuhan dari tiap tiap aktivitas, sehingga pembagian dari organisasi ruang dapat dijelaskan seperti gambar di bawah:

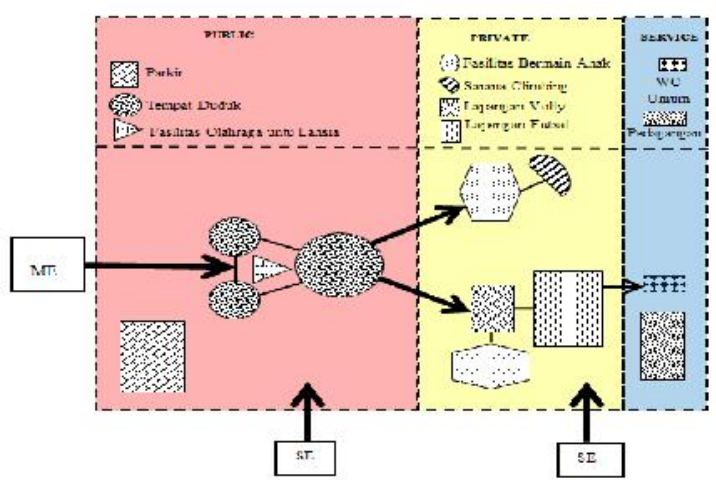

Sumber: Analisis penyusun, 2015

Gambar 3. Organisasi Ruang Taman Tirto Agung

Berdasarkan gambar organisasi ruang di atas, taman Tirto Agung dikelompokan menjadi ruang public, private, dan service. Pengelompokan tersebut memiliki keterkaitan antara suatu ruang dengan ruang lainnya, yang mana dapat dijelaskan berdasarkan tingkat ketebalan garis.Garis yang lebih tebal berarti menunjukan hubungan yang lebih erat, sedangkan garis yang semakin tipis memiliki keterkaitan yang tidak begitu erat.

Pendapat Pakar/ Ahli Tentang Taman Tirto Agung

a. Rina Kurniati (Dosen JPWK Undip), penyedian parkir sepeda motor, fasilitas persewaan mobil mobilan, Kios PKL, fasilitas olahraga untuk lansia, dan penyediaan gazebo. 
b. Prof. Ir. Edy Darmawan, M.Eng (Dosen Jurusan Arsitek Undip), hal hal yang perlu dilakukan penataan yaitu penataan parkir onstreet, dibuat akses menuju sitting group, jarak antar sitting group ke landmark jangan terlalu mepet, penataan PKL bisa diluar taman.

c. Bapak Harry (Sekretaris Bagian Pertamanan, DKP Kota Semarang), menjelaskan tentang sistem penyediaan fasilitas, aturan hukum terkait, serta masukan tentang sistem perawatan pada taman Tirto Agung.

\section{Siteplan Kawasan Taman Tirto Agung}

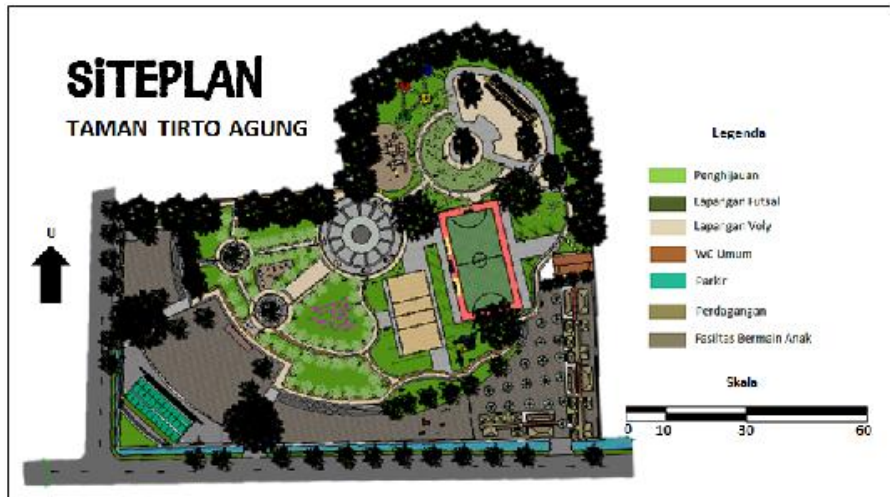

Sumber: Analisis penyusun, 2015

Gambar 4. Siteplan Taman Tirto Agung

\section{Urban Design Guideline}

Tabel 2. Urban Design Guideline

\begin{tabular}{|c|c|c|c|c|}
\hline \multirow[t]{2}{*}{ No } & \multirow[t]{2}{*}{ KOMPONEN } & \multicolumn{2}{|c|}{ DESIGN GUIDELINES } & \multirow{2}{*}{$\begin{array}{c}\text { ATURAN } \\
\text { PENUNJANG }\end{array}$} \\
\hline & & PERFORMANCE & PRESCRIPTIVE & \\
\hline 1 & Landmark & $\begin{array}{l}\text { - Landmark yang terdapat pada } \\
\text { taman Taman Tirto Agung } \\
\text { berupa tulisan “Taman Tirto } \\
\text { Agung” yang di cat putih dan } \\
\text { merah, dan terbuat dari seng } \\
\text { dengan bentuk } 3 \text { dimensi }\end{array}$ & 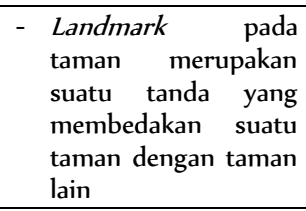 & \\
\hline 2 & $\begin{array}{l}\text { Sirkulasi dan } \\
\text { Parkir }\end{array}$ & $\begin{array}{l}\text { - Parkir mobil berupa parkir on } \\
\text { street } \\
\text { - Parkir sepeda dan sepeda } \\
\text { motor terdapat di dalam } \\
\text { lokasi taman } \\
\text { - Lokasi parkir yang berada di } \\
\text { lokasi taman dibuat dengan } \\
\text { menjorok ke dalam, supaya } \\
\text { view taman Tirto Agung dari } \\
\text { depan tidak terganggu oleh } \\
\text { kendaraan yang sedang parkir } \\
\text { - Alokasi jumlah kendaraan } \\
\text { untuk sepeda motor yaitu } \\
\text { sebanyak } 50 \text { kendaraan, } \\
\text { sedangkan untuk sepeda } \\
\text { terdapat } 10 \text { sepeda. }\end{array}$ & $\begin{array}{l}\text { - Parkir kendaraan } \\
\text { terdiri dari parkir } \\
\text { mobil, sepeda motor, } \\
\text { dan sepeda } \\
\text { - Sirkulasi untuk sepeda } \\
\text { motor yaitu } 50 \% \text { dari } \\
\text { luas lahan parkir }\end{array}$ & $\begin{array}{l}\text { otor dan } \\
\text { eda }\end{array}$ \\
\hline 3 & $\begin{array}{l}\text { Pedagang/ } \\
\text { Activity } \\
\text { Support }\end{array}$ & $\begin{array}{l}\text { - Jumlah stand pedagang } \\
\text { tersebut sebanyak } 20 \text { unit } \\
\text { yang dilengkapi dengan } 20 \\
\text { buah gazebo } \\
\text { - Untuk gazebo yang tersedia } \\
\text { tersebut dapat dibongkar } \\
\text { pasang atau tidak tetap }\end{array}$ & $\begin{array}{l}\text { - Untuk lokasi stand } \\
\text { pedagang } \\
\text { menggunakan lahan } \\
\text { kosong yang terdapat } \\
\text { disebelah } \\
\text { taman. timur } \\
\text { - Di lokasi taman perlu } \\
\text { disediakan tempat } \\
\text { berdagang agar para } \\
\text { pedagang tidak } \\
\text { berjualan } \\
\text { semraut }\end{array}$ & Stand pedagang \\
\hline
\end{tabular}




\begin{tabular}{|c|c|c|c|c|}
\hline \multirow{3}{*}{$\begin{array}{l}\text { No } \\
4\end{array}$} & \multirow[t]{2}{*}{ KOMPONEN } & \multicolumn{2}{|c|}{ DESIGN GUIDELINES } & \multirow[t]{3}{*}{ ATURAN PENUNJANG } \\
\hline & & PERFORMANCE & PRESCRIPTIVE & \\
\hline & $\begin{array}{l}\text { Fasilitas Persewaan } \\
\text { Mobil mobilan }\end{array}$ & $\begin{array}{l}\text { - Penyediaan jasa persewaan mobil } \\
\text { mobilan menggunakan lahan taman } \\
\text { yang berupa pengerasan } \\
\text { - Jasa ini hanya bersifat sementara, hanya } \\
\text { dibuka pada waktu sore dan malam hari }\end{array}$ & $\begin{array}{l}\text { - Fasilitas persewaan mobil } \\
\text { mobilan untuk anak balita, } \\
\text { bersifaat penyediaan jasa yang } \\
\text { disediakan oleh pihak luar. }\end{array}$ & \\
\hline 5 & $\begin{array}{l}\text { Fasilitas Olahraga } \\
\text { untuk Lansia }\end{array}$ & $\begin{array}{l}\text { - Terdiri dari terapi batu dengan lebar } 60 \\
\text { cm } \\
\text { - Terdapat } 4 \text { buah alat fitnees outdor } \\
\text { yang sudah bersifat permanen } \\
\text { - Juga disediakan } 2 \text { buah meja kecil yang } \\
\text { dilengkapi dengan tempat duduk bagi } \\
\text { para pengunjung yang merasa penat, } \\
\text { serta juga terdapat sebuah tempat } \\
\text { sampah. }\end{array}$ & $\begin{array}{l}\text { - Penyediaan fasilitas olahraga } \\
\text { untuk lansia bertujuan untuk } \\
\text { menjaga kesehatan masyarakat } \\
\text { yang telah lanjut usia agar } \\
\text { tetap sehat. }\end{array}$ & \\
\hline 6 & Sitting Group & $\begin{array}{l}\text { - Sitting group utama dibuat dengan } \\
\text { bentuk melingkar dengan diameter } 10 \mathrm{~m} \\
\text { yang memiliki } 8 \text { buah tempat duduk } \\
\text { yang terbuat dari batu } \\
\text { - Sitting group pendukung dibuat secara } \\
\text { melingkar dengan diameter } 6 \mathrm{~m} \text { yang } \\
\text { juga memiliki } 8 \text { tempat duduk }\end{array}$ & $\begin{array}{l}\text { - Berupa kumpulan tempat } \\
\text { duduk yang melingkar, dengan } \\
2 \text { jenis yaitu sitting group } \\
\text { utama dan pendukung }\end{array}$ & s \\
\hline 7 & Taman Bunga & $\begin{array}{l}\text { - Terdiri dari bunga kupu kupu, bunga } \\
\text { kumis kucing, sambiloto }\end{array}$ & $\begin{array}{l}\text { - Taman bunga memiliki } \\
\text { berbagai jenis bunga dengan } \\
\text { warna yang berbeda sehingga } \\
\text { menimbulkan kesan yang indah }\end{array}$ & \\
\hline 8 & $\begin{array}{l}\text { Taman Bermain Anak } \\
\text { Anak }\end{array}$ & $\begin{array}{l}\text { - Taman bermaian terdiri dari beberapa } \\
\text { bentuk permainan yaitu seluncuran, } \\
\text { lorong lorong, jembatan gantung dll. } \\
\text { - Terdapat gazebo di dekat taman } \\
\text { bermain bertujuan untuk tempat duduk } \\
\text { bagi orang tua yang sedang menemani } \\
\text { anaknya bermain }\end{array}$ & $\begin{array}{l}\text { - Terdapat } 2 \text { buah titik taman } \\
\text { bemain anak yaitu sebelah } \\
\text { utara dan selatan. }\end{array}$ & \\
\hline 9 & Lapangan Futsal & $\begin{array}{l}\text { - Pada lapangan futsal ditanam rumput } \\
\text { hijau } \\
\text { - Di dekat lapangan futsal disediakan } \\
\text { tempat duduk/ bangku }\end{array}$ & $\begin{array}{l}\text { - Ukuran lapangan futsal yaitu } \\
25 \mathrm{~m} \times 15 \mathrm{~m}\end{array}$ & \\
\hline 10 & Lapangan Voly & $\begin{array}{l}\text { - Sebagai pembatas anatara lapangan } \\
\text { futsal dan lapangan voly diberi vegetasi } \\
\text { agar bola yang keluar tidak menggangu } \\
\text { aktivitas lain }\end{array}$ & $\begin{array}{l}\text { - Ukuran lapangan voly yaitu } \\
18 \mathrm{~m} \times 9 \mathrm{~m} \text { dengan ketinggian } \\
\text { net } 2.43 \mathrm{~m}\end{array}$ & \\
\hline 11 & $\begin{array}{l}\text { Fasilitas } \quad \text { Wall } \\
\text { Climbing }\end{array}$ & $\begin{array}{l}\text { - Fasilitas wall climbing di cat dengan } 2 \\
\text { warna yaitu merah dan biru supaya } \\
\text { terlihat tidak monoton }\end{array}$ & $\begin{array}{l}\text { - Jarak antar pegangan yaitu } \\
30 \mathrm{~cm}\end{array}$ & \\
\hline 12 & Jogging Track & $\begin{array}{l}\text { - Jogging track terdiri dari pengerasan } \\
\text { yang terbuat dari paving }\end{array}$ & $\begin{array}{l}\text { - Lebar penyediaan jogging track } \\
\text { yaitu } 2 \mathrm{~m}\end{array}$ & \\
\hline 13 & WC Umum & $\begin{array}{l}\text { - WC umum yang tersedia menggunakan } \\
\text { air yang berasal dari PDAM } \\
\text { - Di luar WC umum juga disediakan } \\
\text { tempat untuk cuci tangan }\end{array}$ & $\begin{array}{l}\text { - Terdapat WC umum yang } \\
\text { terdiri dari } 4 \text { pintu }\end{array}$ & \\
\hline 14 & $\begin{array}{l}\text { Sarana untuk Kaun } \\
\text { Difable }\end{array}$ & $\begin{array}{l}\text { - Berupa jalur kuning untuk tuna netra } \\
\text { dengan lebar } 30 \mathrm{~cm} \text { yang mana keramik } \\
\text { yang digunakan yaitu keramik kasar } \\
\text { - Untuk naik ke taman tidak hanya berupa } \\
\text { tangga, tetapi juga disediakan sarana } \\
\text { bagi pengguna kursi roda }\end{array}$ & $\begin{array}{l}\text { - Penyediaan sarana untuk kaum } \\
\text { difable supaya mereka dapat } \\
\text { menikmati fasilitas publik yang } \\
\text { disediakan di taman }\end{array}$ & Jalur untuk difable \\
\hline 15 & Lampu Taman & $\begin{array}{l}\text { - Terdiri dari } 3 \text { buah lampu utama } \\
\text { dengan menggunakan lampu LED. } \\
\text { - Terdapat } 8 \text { buah lampu tengah yang } \\
\text { memberikan kesan balance. } \\
\text { - Terdapat } 40 \text { buah lampu taman model } \\
\text { T yang tersebar di seluruh lokasi taman }\end{array}$ & $\begin{array}{l}\text { - Terdiri dari lampu utama dan } \\
\text { lampu lampu taman kecil } \\
\text { lainnya }\end{array}$ & - \\
\hline
\end{tabular}




\begin{tabular}{|c|c|c|c|c|}
\hline \multirow[t]{2}{*}{ No } & \multirow{2}{*}{ KOMPONEN } & \multicolumn{2}{|c|}{ DESIGN GUIDELINES } & \multirow[t]{2}{*}{ ATURAN PENUNJANG } \\
\hline & & PERFORMANCE & PRESCRIPTIVE & \\
\hline 16 & Tempat Sampah & $\begin{array}{l}\text { - Berupa tempat sampah yang terdiri dari } \\
3 \text { buah dengan } 3 \text { warna yaitu merah } \\
\text { (sampah organik), kuning (sampah } \\
\text { plastik), hijau (sampah umum) } \\
\text { - Terdapat lo buah tempat sampah yang } \\
\text { tersebar di lokasi taman }\end{array}$ & $\begin{array}{lrrr}\text { - Tempat } & \text { sampah } & \text { disediakan } \\
\text { untuk agar tidak ada lagi } & \text { adah } \\
\text { sampah } & \text { sampah } & \text { yang } \\
\text { berserakan } & & & \end{array}$ & \\
\hline 17 & $\begin{array}{l}\text { Pengaturan Vegetasi/ } \\
\text { Tata Hijau }\end{array}$ & $\begin{array}{l}\text { - Vegetasi yang ditanam di pinggir jalan } \\
\text { menggunakan pohon trembesi karena } \\
\text { memiliki daun yang rindang dan kokoh } \\
\text { - Jarak tanam pohon tersebut yaitu } 5 \mathrm{~m} \\
\text { - Vegetasi/ barrier di sebelah utara atau } \\
\text { dekat dengan jalan tol juga } \\
\text { menggunakan pohon yang rindang } \\
\text { sehingga dapat meredam bunyi }\end{array}$ & $\begin{array}{l}\text { - Penanaman vegetasi di } \\
\text { pinggir taman berguna untuk } \\
\text { mengurangi polusi udara dan } \\
\text { suara } \\
\text { - Pengaturan tata hijau yang } \\
\text { terdapat di taman terdiri dari } \\
\text { berbagai jenis tanaman }\end{array}$ & Barrie \\
\hline
\end{tabular}

Sumber: Analisis penyusun, 2015

\section{Kesimpulan dan Rekomendasi}

\section{Daftar Pustaka}

\section{Kesimpulan}

Kegiatan penataan pada taman Tirto Agung mencakup aspek karakteristik pengunjung, elemen pendukung taman, serta aspek perancangan.Setelah dilakukan penelitian dan analisis terhadap permasalahan yang ada, maka dapat diperoleh suatu konsep yang cocok untuk diaplikasikan, yang mana konsep ini diperoleh berdasarkan tinjauan terhadap kondisi fisik di lapangan dan pendapat ahli tentang taman.Analisis tersebut disesuaikan dengan kebutuhan masyarakat terkait fungsi ekologi, fungsi estetika, fungsi kesehatan, fungsi rekreasi dan fungsi ekonomi dari ruang terbuka hijau.Rencana konsep penataan yang akan diterapkan pada taman Tirto Agung ini yaitu "Banyumanik Green Park". Konsep tersebut menjelaskan tentang suatu taman di Banyumanik yang mempertimbangkan aspek hijau/ lingkungan, sehingga taman ini dapat digunakan sebagai wadah bagi aktivitas masyarakat kota dengan penataan lansekap yang dapat meningkatkan nilai estetika dari kawasan tersebut.

\section{Rekomendasi}

Rekomendasi yang dapat diberikan untuk menciptakan suatu kawasan penataan taman Tirto Agung yang baik sebagai ruang publik di Kecamatan Banyumanik Semarang terdiri dari rekomendasi untuk masyarakat/ pengunjung dan rekomendasi untuk pemerintah yaitu sebagai berikut:

1. Rekomendasi untuk masyarakat/ pengunjung

a. Masyarakat/pengunjung agar tetap menjaga kebersihan di lokasi taman.

b. Himbauan untuk seluruh masyarakat agar menjaga semua fasilitas yang ada di taman dengan tidak merusak fasilitas yang telah disediakan.

2. Rekomendasi untuk pemeritah

a. Perlunya dilakukan maintenance (perawatan) terhadap fasilitas yang terdapat pada taman Tirto Agung supaya selalu dalam kondisi baik.

b. Pihak kebersihan kota Semarang agar lebih memperhatikan sampah yang telah menumpuk pada taman Tirto Agung supaya segera untuk di angkut.

c. Diperlukannya suatu aturan yang lebih tegas terhadap para PKL yang masih melanggar untuk tetap berjualan di pinggir jalan Tirto Agung.

Arifin dan Nurhayati. 2000. Pemeliharaan Taman. Penebar Swadaya: Jakarta Budiharjo dan Sujarto 2005. Kota Berkelanjutan. Alumni: Bandung

Dermawan, Edy.2009. Ruang Publik dalam Arsitektur Kota. Semarang: Badan Penerbit Undip Dermawan, Edy. 2014. Visual Estetika Taman Arsitektur Kota. Semarang: Badan Penerbit Undip Hakim, Rustam. 2003. Komponen Perancangan Arsitektur Lansekap. Bumi Aksara : Jakarta Laure, Michael. 1984. Pengantar Kepada Arsitektur Pertamanan. Intermatra: Bandung Neufert, Ernst. 1996. Data Arsitek. Erlangga: Jakarta

Pedoman Ruang Terbuka Hijau di Kawasan Perkotaan (2010)

Peraturan Menteri Pekerjaan Umum No 05/PRT/M/2008 Tentang Pedoman Penyediaan dan Pemanfaatan Ruang Terbuka Hijau di Kawasan Perkotaan

Shirvani, Hamid. 1985. The Urban Design Process. Van Nostrand ReinHold Company: New York 